\title{
Risk and Uncertainty in Travel Decision-Making: Tourist and Destination Perspective
}

\author{
Marion Karl'
}

\begin{abstract}
Many studies on risk and destination choice focus on specific destinations or tourist characteristics in an isolated way, resulting in a fragmented nature in research results without a comprehensive understanding. Therefore, an integrated research approach is applied using tourists' self-assessments of risk and uncertainty in travel decision-making, as well as key characteristics of destinations at hypothetical and realistic stages of the destination choice process. The study uses data collected from a survey on German tourists' destination choice behavior. The results show that high educational levels and high travel frequencies are distinct characteristics of risk-affine tourists, while higher age groups are more dominant in riskand uncertainty-averse tourist types. Tourists with varying attitudes toward risk and uncertainty in travel decision-making differ strongly with respect to ideal destinations initially, but choose rather similar destinations when it comes to the final destination choice.
\end{abstract}

\section{Keywords}

risk, uncertainty, destination choice, travel decision, perception, set theory

\section{Introduction}

Risk and uncertainty in travel decision-making has become an important research area, especially since the terror attacks of September 11, 2001 (Mansfeld 2006), and continue to be relevant, for example, with the recent Arab Spring events and conflicts impacting Mediterranean destinations such as Egypt or Tunisia. There are two dominant strategies that exist in tourism research to study risk and uncertainty in travel decision-making. One branch of research approaches this topic on an aggregated level by investigating real destination choices (DCs) using secondary data from tourist arrivals (Drakos and Kutan 2003; Rittichainuwat and Chakraborty 2009). The focus of this research branch is on a better understanding of the outcome of DC and changes in tourism flows. However, tourists' individual choices not to visit a destination because of high risk levels leading to these changes are not observed. The second strategy therefore approaches the research topic using an individual perspective to address perceptions of risk as an influencing factor of DC (Kozak, Crotts, and Law 2007; Sönmez and Graefe 1998a, 1998b). Such research often either concentrates on the destination itself to investigate risk categories (Fletcher and Morakabati 2008) or on specific tourist groups with similar attitudes, perceptions, or behaviors toward risk (Fuchs 2013; Jonas et al. 2011). While all studies agree that risk and uncertainty play an important role in DCs, the question of how and when these factors influence tourists in their decisions whether or not to visit certain destinations are ambiguous and often the results are contradictory (e.g., the influence of sociodemographic factors such as age or gender).

Some of the reasons for the fragmentary nature of past research may be due to the fact that various conceptual or methodological approaches are applied. First, numerous studies make either-or decisions regarding the analysis of hypothetical or real DCs, which is problematic because of an existing discrepancy between hypothetical desired holidays versus actually executed holidays (Karl, Reintinger, and Schmude 2015). Second, either-or decisions are made about a focus on certain tourists or destinations, which is controversial seeing that $\mathrm{DC}$ is considered a negotiation process between tourists' needs and amenities offered by destinations (Bekk, Sporrle, and Kruse 2015). Lastly, either-or decisions are made about the research methodology between the survey of self-assessments or actual DC behaviors, which is particularly precarious with regard to social desirability as a

\footnotetext{
'LMU Munich, Department of Geography, Munich, Germany

Corresponding Author:

Marion Karl, Research Assistant, LMU Munich, Department of Geography, Luisenstrasse 37, 80333 Munich, Germany.

Email: marion.karl@Imu.de
} 
factor in surveys that retrieve personal estimations of individual attitudes or behaviors.

Therefore, an integrated research approach is applied in this study that avoids either-or decisions about these aspects. By looking at hypothetically considered destinations at the beginning of the DC process as well as the actually planned or executed DCs at the end of the process, this study is able to shed light on the way and the timing of risk and uncertainty as influencing factors of DC. Furthermore, the combination of a tourist and destination perspective allows investigations of interdependencies between tourists' personalities and destination attributes under the influence of risk and uncertainty to understand why certain types of destinations are chosen or rejected during the DC process by tourists with a certain level of risk and uncertainty affinity. Lastly, the inclusion of tourists' self-assessments of risk and uncertainty in travel decision-making, as well as key characteristics of destinations considered at different stages of the DC process, allows the assessment of discrepancies between individual imagination and actual travel behavior caused by risk and uncertainty.

The research is guided by three main research aims focusing on

1. The development of a tourist typology based on respondents' self-assessments of concepts related to risk and uncertainty in travel decision-making,

2. The profiling of significant determinants of the tourist typology based on tourists' sociodemographic and travel-related characteristics, and

3. The identification of differences between the tourist types in the hypothetical and realistic stages of the $\mathrm{DC}$ processes based on destination characteristics.

To achieve these research aims, the study uses data from a survey on German tourists' self-assessments of travel decision-making with regards to risk and uncertainty, and actual DC behaviors. Based on a literature review, several items related to risk and uncertainty in travel decision-making are chosen and used to develop the tourist typology. For a better understanding of the tourist types, sociodemographic and travel-related factors are tested to determine relations between tourist type and tourist characteristics. Alternative destinations on several stages of the DC process, representing rather hypothetical or realistic choices, are further investigated to depict differences in DCs between the tourist types. To capture the destination itself, destinations that are considered during the DC process are characterized using an objective index on familiarity and uncertainty.

\section{Literature Review}

The first part of the literature review discusses why DC should be investigated from a tourist and destination perspective. The second part outlines the role of risk and uncertainty in travel decision-making and DC, while the third part introduces several concepts relating to risk that are of relevance for this study.

\section{Tourist and Destination Perspective in Destination Choice Research}

DC is based on a negotiation process between tourists' needs and amenities offered by destinations (Ankomah, Crompton, and Baker 1996). Bekk, Sporrle, and Kruse (2015) follow this idea and propose a theoretical model for examining tourist behavior that recognizes the interplay between destination and tourist characteristics as an influencing factor of tourist behavior. Their study is based on perceived similarity of brand dimensions and could be expanded to actual features that characterize destinations. Butler $(2012,30)$ criticizes a general negligence of the spatial dimension in tourism research since tourism "is about the places from which they [tourists] come and even more the places to which they go, ... and as geographers I would argue it is essential that we focus on these aspects beyond all others." However, there are few studies on risk and uncertainty in DC that investigate DC as a negotiation process between tourists' needs and destinations' amenities, and destination information is included to a limited extent (Lo, Cheung, and Law 2011; Lo, Law, and Cheung 2011; Roehl and Fesenmaier 1992). For example, Lo, Law, and Cheung (2011) consider the destination as a travel-related determinant; however, whether tourists visit a national or international destination was the main destination characteristic that was further tested.

While the isolated treatment of destination and tourist characteristics allows us to gain insight into specific aspects and their function in the DC process, it impedes the understanding of the complex role of risk and uncertainty during the DC process. Following the basic assumption of an interplay between tourist and destination, this study focuses on the question why tourists decide to visit destinations with a certain level of risk depending on factors relating to the tourist or the destination. Therefore, this study incorporates key destination attributes influencing DCs in the context of risk and uncertainty, such as familiarity and relevant tourist characteristics, such as risk and uncertainty affinity.

\section{Risk and Uncertainty in Travel Decision-making and Destination Choice}

The focus of this study is on risk and uncertainty because these factors play an important role in many stages of the travel decision-making process, specifically during the DC (Quintal, Lee, and Soutar 2010), one of the most important subdecisions of the multistage travel decision-making process (Crouch, Huybers, and Oppewal 2016). An important aspect of DC of relevance for studies on risk and uncertainty is that tourists are not able to predict or anticipate the 
situation at a destination before traveling, and therefore rely on information from other sources, such as media, friends and family members, or travel organizations. In cases where the perceived situation is not acceptable or desirable for the tourist, tourists will modify their travel plans (Mansfeld 2006) depending on the stage of their travel decision. Before a final choice is made, tourists may decide to travel to a different destination and find a substitute for an alternate destination (Decrop 2010). After the final choice is made, tourists may then choose to travel to the same destination but, at another time, alter their travel plans by shifting from traveling individually to booking a package tour, or from traveling alone to traveling in groups (Adam 2015). Other important strategies after the final choice are purchasing travel insurance, bringing extra cash, and searching for the latest information about the destination (Lo, Cheung, and Law 2011).

Risk and uncertainty are often used interchangeably (Quintal, Lee, and Soutar 2010). However, risk refers to assessments of possibilities that certain (negative) events occur (Weber and Bottom 1989), whereas uncertainty refers to partial knowledge during the decision-making process (Crompton 1992). Uncertainty is relevant for DCs as it can arise in situations where tourists are exposed to an overload of information which they are not able to process (Crompton 1992), or from specific characteristics of traveling such as intangibility, inseparability, variability, and perishability of the product travel (Fuchs and Reichel 2006). In regard to risk and DC, Sönmez and Graefe (1998a, 125) state that "potential tourists select the destination which best matches their needs by offering the most benefits for the least cost (or risk)." Past studies on risk and DC consider various risk factors such as the risk that a holiday would not provide personal satisfaction. However, risk factors that affect tourists' physical well-being are the strongest influencing factors of DC (Gray and Wilson 2009); therefore, this study focuses mainly on such safety and security risks.

Focusing on the perception of the situation is important in the context of risk, as risk perceptions (i.e., subjective assessment from an individual's perspective and the likelihood of negative consequences of an event or choice; Mowen and Minor 2001) are proven to be stronger determinants of DC than actual existing risks (Fuchs and Reichel 2006). Studies on risk (perceptions) and DC agree that risk influences DC (Floyd et al. 2004; Fuchs and Reichel 2006; Kozak, Crotts, and Law 2007; Sönmez and Graefe 1998a, 1998b) but do not agree on the strength or the manner of the influence: A study by Floyd et al. (2004) in the aftermath of the September 11 terrorist attacks shows tourists avoid international travel if the level of perceived risk is too high. However, further research reveals that high levels of risk or perceived risk only lead to a substitution of travel destinations but not a canceling of all (international) travel plans (Drakos and Kutan 2003; Rittichainuwat and Chakraborty 2009). General leisure constraint theories may provide more insight. Translating Crawford, Jackson, and Godbey's (1991) hierarchical model of leisure constraints to the context of risk and uncertainty implies that intrapersonal constraints including risk perceptions affect travel intentions and DCs at the beginning of the process while interpersonal (e.g., suitable travel partner) or structural constraints (e.g., financial situation) become stronger toward the final decision.

So far research is not able to identify whether risk (perception) has the strongest influence on DCs at the beginning of the DC process when tourists dream about hypothetical holidays, toward the end of the DC process when tourists actively consider alternatives for a certain holiday, or at the last step when tourists overcome all constraints and choose one final destination. To address this research gap, this study focuses on hypothetical and realistic DCs, based on the assumption that a discrepancy exists between those DCs (Karl, Reintinger, and Schmude 2015), to investigate when risk and uncertainty trigger changes in tourists' DCs.

Hypothesis 1: Tourists with higher levels of risk and uncertainty affinities in travel decision-making consider destinations with lower levels of risk and uncertainty for hypothetical future holidays.

Hypothesis 2: A high level of risk is a constraining factor in realistic DCs for tourists with a low level of risk and uncertainty affinity in travel decision-making.

Many studies dealing with risk perception and DC concentrate on risk categories as possible generators or sources of risk at a destination such as natural disasters (Park and Reisinger 2010), health risks (Jonas et al. 2011), criminality (Ryan 1993), political instability (Fletcher and Morakabati 2008), or terrorism (Fuchs et al. 2013). The results of many past studies are connected to a specific research context and often are either spatially restricted by the investigation of case studies or restricted by the sample through the investigation of specific tourist groups. Case studies of specific destinations (Fuchs 2013; Sharifpour et al. 2014) may affect the results because DC is influenced by a variety of factors that could outweigh the influence of risk and uncertainty, which is often not controlled for in case studies. Moreover, research focuses on certain groups of tourists with high influence of risk on DC, such as visitors of a medical clinic concerned about health risks (Jonas et al. 2011), or low influence of risk on DC, such as tourists traveling to a region affected by terrorism (Fuchs et al. 2013). The focus on specific tourist groups is insofar problematic as past research has shown that risk perceptions are influenced by sociodemographic variables such as age (Hajibaba et al. 2015; Reisinger and Mavondo 2006), gender to some degree (Lepp and Gibson 2008; Pizam et al. 2004), or educational level (Park and Reisinger 2010; Sönmez and Graefe 1998a).

Although most studies agree that sociodemographic variables influence risk perceptions, results are sometimes ambiguous, which might be due to a focus on certain age groups, as one explanation. Therefore, this study aims to further clarify 
these results by including sociodemographic variables as explanatory factors of tourists' attitudes and behaviors toward risk and uncertainty in travel decision-making.

Hypothesis 3: The level of risk and uncertainty affinity in travel decision-making is related to the tourists' gender.

Hypothesis 4: The level of risk and uncertainty affinity in travel decision-making decreases with increasing age.

Hypothesis 5: The level of risk and uncertainty affinity in travel decision-making increases with the tourists' educational levels.

Hypothesis 6: The level of risk and uncertainty affinity in travel decision-making is related to the tourists' professions. Hypothesis 7: The level of risk and uncertainty affinity in travel decision-making is related to the tourists' household incomes.

Aside from sociodemographic variables, risk perceptions are influenced by factors related to traveling such as traveling with children or travel experience. Past research conducted by Roehl and Fesenmaier (1992) has shown that tourists focus on different kinds of risks depending on whether or not they are traveling with young children. In particular, functional risks such as organizational difficulties at the destination are most concerning for travelers with young children. Roehl and Fesenmaier (1992) do not differentiate between age groups and focus on young children. However, tourists traveling with older children may be affected in their risk and uncertainty attitudes or behaviors. This study therefore aims to investigate the factor "traveling with children" in a more differentiated way to understand how it affects risk and uncertainty affinity and DCs.

Hypothesis 8: Traveling with children is related to tourists' risk and uncertainty affinity in travel decision-making.

Several past studies demonstrate that travel experience influences, at least, some dimensions of risk perception (Fuchs and Reichel 2011; Rittichainuwat and Chakraborty 2009; Sönmez and Graefe 1998a, 1998b). Moreover, Lo, Cheung, and Law (2011) found that not all tourists apply the same risk reduction strategies, and differences exist, for example, as seen between experienced and inexperienced travelers. One explanation can be taken from the concept of self-efficacy by Bandura (1977), which states that the accomplishment of a certain situation and repeated success strengthen the belief in someone's own skills and strongly influences their behavior. Since self-efficacy belief is transferable to other situations, inexperienced tourists may cautiously approach more and more "difficult" destinations through the establishment of self-efficacy by visitation of other destinations. This implies that travel experience, risk perception, and DC are interconnected. An increase in travel experience lowers the level of perceived risk and leads to the choice of destinations with higher levels of risk for future holidays, which then increases travel experience even further. However, while travel experience was detected as an influencing factor of risk perceptions, the influence on risk and uncertainty affinity is not yet clear. Therefore, this study integrates past travel experience as a direct influencing factor of attitudes and behavior toward risk and uncertainty in travel decision-making and an indirect determinant of DCs.

Hypotheses 9: Gaining travel experience increases tourists' risk and uncertainty affinity in travel decision-making.

\section{Concepts Relating to Risk and Uncertainty Relevant for Destination Choices}

Yang and Nair's (2014) review of risk in tourism states that risk and risk perception are multidimensional concepts related to aspects such as uncertainty avoidance, worry, anxiety, or fear. Other aspects that are associated with risk are sensation seeking (Fuchs 2013), risk-taking propensity (Pizam et al. 2004), and familiarity seeking (Plog 1974, 2001).

Uncertainty avoidance is defined as the extent to which someone feels threatened or uncomfortable by ambiguous, unknown, or uncertain situations (Hofstede, Hofstede, and Minkov 2010). Consequently, persons with high uncertainty avoidance refrain from situations where the outcome is not clearly predictable. From a DC context, this could mean tourists may decide not to travel to destinations with less developed touristic infrastructures as it is more difficult to estimate or predict the outcome of a holiday in such a destination. Another strategy to reduce uncertainty can be derived from risk reduction strategies such as traveling with a tour operator instead of individual traveling (Adam 2015; Lo, Cheung, and Law 2011). Here, lack of knowledge about the destination is compensated by engaging a professional travel agent and tour guide.

The concept of familiarity is another important aspect related to risk and uncertainty due to how destination characteristics and tourist needs interact within the DC process. Plog $(1974,2001)$ determined that familiarity- and noveltyseeking behavior is reflected in DC, as well-known destinations are chosen by familiarity-seeking tourists and unknown destinations by novelty-seeking tourists. Plog's (1974) focus on the development of destinations moreover reveals that novelty seekers dominate in the beginning of a destination's lifecycle versus familiarity seekers at the end. One possible explanation for this outcome may be that well-known destinations with a history of tourism can provide sufficient tourism infrastructure and are therefore chosen by familiarity seekers. Karl, Reintinger, and Schmude (2015) operationalize Plog's $(1974,2001)$ familiarity concept to investigate tourists' DCs and show that most tourists prefer traveling to rather familiar destinations, yet dream about visiting destinations with different levels of familiarity. Morakabati and Kapuściński (2016) seize on Plog's $(1974,2001)$ typology to analyze differences in risk perceptions, benefits sought from 
a holiday, and a terrorism effect depending on the type of tourist. Their results emphasize the relation between familiarity and risk perception, revealing that familiarity-seeking tourists tend to have significantly higher risk perceptions than novelty-seeking tourists.

Sensation seeking and risk-taking propensity are two concepts that refer more to attitudes and behaviors rather than mere perception. Sensation seeking describes the "generalized tendency to seek varied, novel, complex, and intense sensations and experiences and the willingness to take risks for the sake of such experiences" (Zuckerman 2010, 1545), whereas risk-taking propensity is the generic orientation or attitude of a person toward taking or avoiding risks (Rohrmann 2008). This implies that risk may be a positive asset of traveling or a travel motive for some tourists (Adam 2015). As it pertains to DC, high sensation seeking and risktaking tendencies may direct tourists toward new and unknown destinations with little touristic infrastructure that pose a certain risk instead of revisiting familiar destinations. Hajibaba et al. $(2015,49)$ analyze risk-taking propensity on a group of tourists visiting a highly volatile destination and found that such crisis-resistant tourists "tend to absorb risks instead of engaging in risk avoidance strategies." This implies that these tourists are not attracted by the risk but attracted to the destination despite the risk. Regarding on-site behavior, Pizam et al. (2004) study risk-taking and sensation seeking in form of a combined influencing factor of tourist behavior and are able to show that tourists with high risktaking and sensation seeking tendencies are more likely to engage in adventurous activities that might pose a certain level of risk. A study conducted by Lee and Tseng (2015) furthermore reveals that how tourists evaluate situations with a certain level of risk or uncertainty influences the degree to which tourists engage in activities with dangerous or uncertain results.

All these concepts have been covered in research but mostly not in a complementary way, and focus on one factor interrelated to others creates research results that are sometimes difficult to interpret on a more comprehensive scale. Furthermore, many of these concepts overlap and this study therefore combines these concepts for the development of the tourist typology (Table 1) to reveal the role of risk and uncertainty in DC.

\section{Methodology}

\section{Research Design}

An integrated research model was developed in which hypothetical and realistic DCs are investigated from a tourist and destination perspective (Figure 1). A tourist typology is developed based on literature on several concepts related to risk and uncertainty in travel decision-making. The tourist types are then profiled regarding specific sociodemographic and travel-related characteristics before DCs are analyzed using a destination index that characterizes destinations according to their level of familiarity. The separate components of the research model will be described in the following sections.

Development of the tourist typology. The tourist typology is based on risk and associated aspects as influencing factors of travel decision-making behavior. The chosen items (Table 1) refer to uncertainty avoidance, sensation seeking, novelty seeking, and risk-taking propensity during the travel decision-making process, as outlined in the literature review. All items were measured using a semantic differential technique (5-point scale) stating how much a respondent would prefer each contrasting option. To avoid a bias caused by the wording of the items, statements started with risk and uncertainty averse as well as affine options. The scores were later reversed to obtain meaningful scores.

The items represent three dimensions of travel decisionmaking: type of destination, type of holiday, and on-site behavior. Table 1 provides the dimensions and items incorporated in the tourist typology with literature examples for the concepts and methodology that supported the development of the items.

The type of destination is represented by three items. The first item refers to tourists' needs for familiarity or sensation and can be best explained using Plog's (1974) tourist typology, which suggests familiarity-seeking tourists choose destinations with a high level of familiarity, which they can find in destinations that they have already visited before (item 1). The second item regarding destinations' touristic infrastructures is derived from the concept of uncertainty avoidance (Quintal, Lee, and Soutar 2010), which assumes tourists with higher uncertainty avoidances prefer destinations with welldeveloped touristic infrastructures to facilitate traveling and to reduce the level of uncertainty (item 2). The third item directly refers to safety and security levels at a destination with risk-taking propensity as a theoretical concept (Williams and Baláž 2013) and derived from a study conducted by Hajibaba et al. (2015) on crisis-resistant tourists who decide to visit a destination despite safety concerns (item 3 ).

The type of holiday is represented by items on the preplanning process and travel organization. Preplanning is based on the category experience seeking from Zuckerman's (1971) sensation-seeking scale. It is assumed that traveling without a thorough preplanning expense adds a certain level of sensation appealing to high sensation seeking tourists (item 4). Hofstede's concept of uncertainty avoidance is applied in this study for the item "travel organization." The assumption is that tourists who prefer to travel with tour operators instead of organizing the holiday themselves are more averse to uncertainty (item 5) since the organizer is responsible for tourists' safety and will avoid potential threats or inform tourists when necessary.

On-site behavior is represented by two items where the first deals with the kind of activities located at 
Table I. Operationalization of the Tourist Typology with Literature Examples for the Concepts and Methodology.

\begin{tabular}{|c|c|c|c|c|}
\hline Item No. & $\begin{array}{l}\text { Item Description: I Prefer ... } \\
\text { (Measured on a 5-Point Scale) }\end{array}$ & $\begin{array}{l}\text { Dimension: Travel } \\
\text { Decision-making }\end{array}$ & $\begin{array}{l}\text { Dimension: Risk } \\
\text { and Uncertainty }\end{array}$ & $\begin{array}{l}\text { Literature: Conceptual and } \\
\text { Methodological }\end{array}$ \\
\hline 1 & $\begin{array}{l}\text { To revisit destinations or destinations } \\
\text { that I have not yet visited. }\end{array}$ & Type of destination & $\begin{array}{l}\text { Novelty seeking } \\
\text { Sensation seeking }\end{array}$ & $\begin{array}{l}\text { Lepp and Gibson 2008; Zuckerman } \\
\text { |97I }\end{array}$ \\
\hline 2 & $\begin{array}{l}\text { Destinations with highly developed } \\
\text { touristic infrastructures or destinations } \\
\text { with less developed touristic } \\
\text { infrastructures. }\end{array}$ & Type of destination & $\begin{array}{l}\text { Uncertainty } \\
\text { avoidance } \\
\text { Novelty seeking }\end{array}$ & $\begin{array}{l}\text { Plog 1974, 2001; Quintal, Lee, and } \\
\text { Soutar } 2010\end{array}$ \\
\hline 3 & $\begin{array}{l}\text { Destinations despite safety concerns or } \\
\text { destinations with high safety levels. }\end{array}$ & Type of destination & $\begin{array}{l}\text { Risk-taking } \\
\text { propensity }\end{array}$ & $\begin{array}{l}\text { Hajibaba et al. 2015; Williams and } \\
\text { Baláž } 2013\end{array}$ \\
\hline 4 & $\begin{array}{l}\text { Preplanned trips or trips without definite } \\
\text { route or timetables. }\end{array}$ & Type of holiday & Sensation seeking & $\begin{array}{l}\text { Lepp and Gibson 2008; Pizam et al. } \\
\text { 2004; Zuckerman 1971 }\end{array}$ \\
\hline 5 & $\begin{array}{l}\text { Travel organization through tour } \\
\text { operators or individual independent } \\
\text { organization. }\end{array}$ & Type of holiday & $\begin{array}{l}\text { Uncertainty } \\
\text { avoidance } \\
\text { Novelty seeking }\end{array}$ & $\begin{array}{l}\text { Cohen 1972; Lepp and Gibson 2008; } \\
\text { Lo, Law, and Cheung 20I I; Seabra } \\
\text { et al. } 2013\end{array}$ \\
\hline 6 & $\begin{array}{l}\text { Exciting activities that might be } \\
\text { dangerous or safe activities which } \\
\text { might be less exciting. }\end{array}$ & On-site behaviour & $\begin{array}{l}\text { Sensation seeking } \\
\text { Risk-taking } \\
\text { propensity }\end{array}$ & $\begin{array}{l}\text { Fuchs 2013; Jackson, Hourany, and } \\
\text { Vidmar 1972; Lee and Tseng 20 I5; } \\
\text { Lepp and Gibson 2008; Pizam et al. } \\
\text { 2004; Zuckerman 197I }\end{array}$ \\
\hline 7 & $\begin{array}{l}\text { Unfamiliar local food or familiar } \\
\text { international food. }\end{array}$ & On-site behaviour & $\begin{array}{l}\text { Uncertainty } \\
\text { avoidance } \\
\text { Novelty seeking }\end{array}$ & $\begin{array}{l}\text { Larsen et al. 2007; Lepp and Gibson } \\
\text { 2003, } 2008\end{array}$ \\
\hline
\end{tabular}

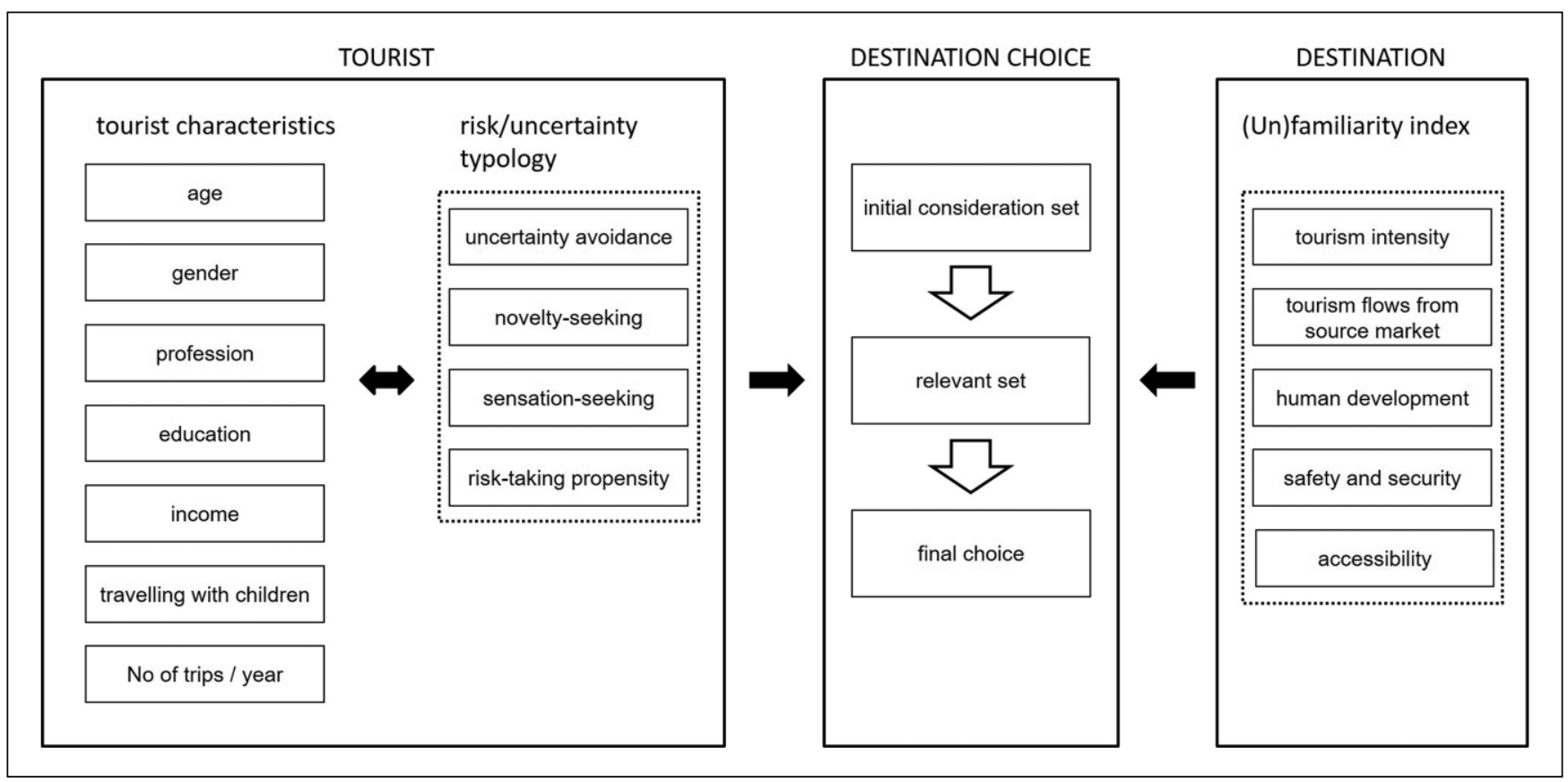

Figure I. Research model.

the destination. The theoretical concepts used here are the categories of thrill and adventure seeking from Zuckerman's (1971) sensation-seeking scale and the physical risk-taking propensity from the Jackson Personality Inventory (Jackson, Hourany, and Vidmar 1972). An item on activities was chosen in part because of research conducted by Crouch,
Huybers, and Oppewal (2016), where the choice of activity and choice of destination are identified as fundamental aspects of travel decision-making. The operationalization of sensation seeking and risk taking during traveling is derived from the results of a study conducted by Pizam et al. (2004) revealing sensation seeking and risk taking being related to 
engagement in risky activities. The assumption is that tourists who choose activities with a certain level of risk are more risk affine than tourists who choose safe activities (item 6). The second item relating to on-site behavior includes uncertainty avoidance and novelty seeking with regard to food preferences at the destination. The supposition is that unknown local food is a positive asset of traveling for novelty-seeking tourists and a potential source of risk for tourists with high uncertainty avoidances (item 7). It is partially based on Lepp and Gibson's (2003) study that reveals strange food being a concern particularly for tourists with high familiarity needs while it is not relevant for other tourists. Since food risks are perceived to be higher abroad than at home (Larsen et al. 2007), concern about food was operationalized using the terms unfamiliar local food versus familiar international food.

Analysis of destination choice. Set theory was applied to investigate DC as it allows to focus on the process rather than the outcome of the choice process (Karl, Reintinger, and Schmude 2015). Reasons for the rejection of destinations at certain stages can be identified further to clarify as to when and how risk and uncertainty affect the DC process. In set theory, DC is treated as a multistage process where alternative destinations are grouped into hierarchically ordered sets that gradually reduces the complexity of the DC (e.g., Crompton 1992; Crompton and Ankomah 1993). The focus for this study is on DC sets that permit capturing differences between hypothetical future, realistically planned, and actually executed DC behaviors known as initial consideration set, relevant set, and past DC.

The initial consideration set represents rather hypothetical choices at the beginning of the DC process, built from destinations respondents would like to visit in the future (Karl, Reintinger, and Schmude 2015). Similar to Crompton's (1992) initial set, it is created before the DC for an actual trip is activated. The initial consideration set is able to illustrate the range of destinations respondents are drawn to without consideration of temporal constraints that might be immediate deterrents to travel at the present time.

Initial consideration set: "Please name up to six other destinations that you would like to visit in the future."

In contrast to the hypothetical initial consideration set, the relevant set refers to planned choices relating to a specific holiday containing all alternative destinations which are considered for this trip. The relevant set is based on the late consideration set (Ankomah, Crompton, and Baker 1996; Crompton 1992) as a limited time frame between choice and start of the holiday is included, with a maximum of 12 months used for this study. The importance of relevant sets in DC stems from the fact that the final destination is ultimately taken from this set (Crompton 1992).
Relevant set: "Which are/were alternative destinations for your next main holiday (i.e., at least four overnight stays)?"

Besides travel plans, respondents' past DCs (i.e., main holidays of the last three years) were included to represent the actual finalized choices. Past DCs display a highly realistic image of the DC without destinations that are not suitable for the respondent because of temporal or permanent constraints. Past DCs not only represent the geographical dimensions of travel behavior but also allow for drawing conclusions on travel frequencies and travel experience. Travel frequency, measured as the number of main holidays in the past three years, is based on past studies by Floyd et al. (2004), Pizam et al. (2004), or Sönmez and Graefe (1998a). Respondents were not restricted to a specific geographical scale concerning the destinations in the questionnaire as destinations "come in all shapes and sizes and can be found in a variety of geographical settings" (Fyall 2013, 118).

To test whether tourist types differ significantly regarding the alternative destinations of hypothetical, planned, and executed DC, destinations are categorized according to a destination index from a former study by Karl, Reintinger, and Schmude (2015) that captures the level of (un)familiarity toward destinations from German tourists' perspectives. The destination index operationalizes Plog's $(1974,2001)$ familiarity concept to develop an objective categorization of destinations based on secondary data. The destination index is based on a cluster analysis of indicators for tourism intensity (UNWTO 2013a), tourism flows from Germany (UNWTO 2013b), human development (UNDP 2013), accessibility, and safety/security (IEP 2013). The destination index distinguishes five types of destinations that vary in their distance to the source market Germany, general importance as a holiday destination, experience of German tourists with a destination, development status, and safety/security level. Table 2 displays the key characteristics of the destination categories with exemplary countries. The destination index was used to investigate DC processes of the respondents to capture what type of destination is most relevant for each tourist type in each DC set. All destinations mentioned in the survey are aggregated on the national level for the application of the destination index.

\section{Data Collection}

A quantitative survey was conducted in Munich, Germany, in June $2014(n=402)$ using a standardized questionnaire in personal interviews. The survey took place when no major natural disaster or man-made safety and security issue occurred or was discussed in the German media. This is insofar important as judgments of destinations in regard to risk and uncertainty are often highly influenced by current events, especially by the media representation of these events (Hall and O'Sullivan 1996). Specially trained interviewers 
Table 2. Description of Destination Index with Key Characteristics and Locations.

\begin{tabular}{lcl}
\hline Category & \multicolumn{1}{c}{ Key Characteristics } & \\
\hline Easy travel & $\begin{array}{c}\text { Very safe, very highly developed, short distance to Germany, } \\
\text { high tourism intensity, strong tourist flow from Germany }\end{array}$ & $\begin{array}{l}\text { Western Europe, Central Europe } \\
\text { e.g., Germany, France }\end{array}$ \\
Out-of-the-ordinary & $\begin{array}{l}\text { Rather unsafe, highly developed, medium distance to Germany, } \\
\text { low tourism intensity, weak tourist flow from Germany }\end{array}$ & $\begin{array}{l}\text { Eastern Europe, North Africa, Middle East } \\
\text { e.g., Albania, Macedonia }\end{array}$ \\
Safe adventure & Very safe, very highly developed, long distance to Germany, & North America, Australasia, South America \\
& low/medium tourism intensity, medium/weak tourist flow & e.g., USA, New Zealand, Chile \\
from Germany & South America, Central America, Sub- \\
Tricky discovery & Unsafe, less developed, long distance to Germany, low tourism & Saharan Africa, South/Southeast Asia \\
& intensity, weak tourist flow from Germany & e.g., Colombia, Vietnam \\
No go & Africa, Asia \\
& Gery unsafe, less developed, medium/long distance to & e.g., Syria, Iraq \\
\hline
\end{tabular}

Source: Karl, Reintinger, and Schmude 2015.

approached the respondents using a random sampling strategy. The interviews took place in 15 public spaces where people tend to spend time instead of just passing. This research setting allows respondents to reflect on their DC processes to uncover subconsciously executed DCs. A screening question ensured that only potential tourists who were planning to travel within the next 12 months for at least four overnight stays participated in the survey. Only potential tourists at the age of 14 or older were included since children influence but are not actively involved in DCs (Decrop 2006).

Technical and comprehension-related pilot tests were conducted to improve the reliability and validity of the questionnaire. The questionnaire comprises four sections (13 questions with secondary questions): The first section focuses on actual DCs using the set approach as theoretical base, while the second section concentrates on risk and uncertainty in travel decision-making. Please note that the third section on risk assessments of travel destinations is not part of this article. The fourth section collects sociodemographic information. The questionnaire was completed in an average time of 10 minutes. Table 3 illustrates the profile of respondents. The age group 20-29 years is particularly dominant since the survey took place in a city with a high student population. However, the bias in the sample is not relevant for the further cluster analysis since no conclusions are drawn from the sizes of the clusters.

\section{Data Analysis}

A cluster analysis is carried out to develop a tourist typology that differentiates tourists according to various aspects associated with risk as outlined in the research design section. All items described in Table 1 are included in the cluster analysis. Hierarchical cluster analysis following Ward's minimum variance method is applied with squared Euclidean distance measure since similarity is defined by the net distance between values. To test the validity of the cluster analysis, multiple discriminant analysis is carried out for confirming the classification reliability, resulting in a high percentage $(88.2 \%)$ of correctly classified cases.

The tourist typology is tested for significant determinants both from the tourist and destination perspective to profile tourist types based on sociodemographic and travel-related characteristics, to identify significant factors that distinguish the tourist types, and to investigate differences in DCs. Pearson's chi-squared tests are conducted for all variables except for the metric variables age and number of trips in the past three years. Here, homogeneity of variances as a precondition for one-way analysis of variance (ANOVA) is not given; therefore, Kruskal-Wallis one-way ANOVA as a nonparametric method is applied to explore differences between ages and travel frequencies among tourist types.

\section{Results}

The objectives of this study were to develop a tourist typology based on concepts relating to risk that would be further investigated for significant determinants to identify differences in tourist characteristics and DCs between the tourist types.

\section{Tourist Typology}

The cluster analysis of respondents' self-assessment of several aspects associated with risk in travel decision-making (Table 1), which was conducted to segment tourists according to their risk and uncertainty affinity, reveals five types of tourists from avoidance of risk and uncertainty to high risktaking tendencies. Table 4 displays the results of the cluster analysis with mean scores and standard deviations, calculated for each tourist type, for each item (Table 1) of the tourist typology.

Risk and uncertainty avoiders are characterized by values directing at risk aversion, sensation and uncertainty avoidance, as well as familiarity seeking. Among all tourist types, the risk and uncertainty avoider has the strongest preference 
Table 3. Profile of Respondents $(n=402)$.

\begin{tabular}{|c|c|c|}
\hline & $n$ & $\%$ \\
\hline \multicolumn{3}{|l|}{ Gender } \\
\hline Female & 205 & 52.4 \\
\hline Male & 186 & 47.6 \\
\hline \multicolumn{3}{|l|}{ Age, years } \\
\hline $14-19$ & 18 & 4.5 \\
\hline $20-29$ & 177 & 44.5 \\
\hline $30-39$ & 66 & 16.6 \\
\hline $40-49$ & 41 & 10.3 \\
\hline $50-59$ & 44 & II.I \\
\hline $60-69$ & 30 & 7.5 \\
\hline$>69$ & 22 & 5.5 \\
\hline \multicolumn{3}{|c|}{ Highest level of education achieved } \\
\hline Apprenticeship & 9 & 2.3 \\
\hline Junior high school & 13 & 3.3 \\
\hline Secondary school & 68 & 17.4 \\
\hline High school & 153 & 39.2 \\
\hline University or college & 140 & 35.9 \\
\hline Other & 7 & 1.8 \\
\hline \multicolumn{3}{|l|}{ Occupation } \\
\hline Retired & 31 & 30.6 \\
\hline House wife/husband & 15 & 3.8 \\
\hline Student & 120 & 30.6 \\
\hline Pupil & 8 & 2.0 \\
\hline Apprentice & 19 & 4.8 \\
\hline Employee, civil servant & 158 & 40.3 \\
\hline Self-employed & 29 & 7.4 \\
\hline Unemployed & 8 & 2.0 \\
\hline Other & 4 & 1.0 \\
\hline \multicolumn{3}{|c|}{ Household income per month, $€$} \\
\hline$<750$ & 68 & 17.0 \\
\hline $750-1,499$ & 50 & 12.5 \\
\hline $1,500-1,999$ & 41 & 10.3 \\
\hline $2,000-2,499$ & 26 & 6.5 \\
\hline $2,500-2,999$ & 31 & 7.8 \\
\hline $3,000-3,499$ & 27 & 6.8 \\
\hline $3,500-3,999$ & 25 & 6.3 \\
\hline $4,000-4,499$ & 23 & 5.8 \\
\hline $4,500-4,999$ & 21 & 5.3 \\
\hline $5,000-7,499$ & 24 & 6.0 \\
\hline$>7,499$ & II & 2.8 \\
\hline $\mathrm{n} / \mathrm{s}$ & 52 & 13.0 \\
\hline \multicolumn{3}{|l|}{ Household size } \\
\hline 1 & 150 & 37.8 \\
\hline 2 & 103 & 25.9 \\
\hline 3 & 59 & 14.9 \\
\hline 4 & 62 & 15.6 \\
\hline$>4$ & 23 & 5.9 \\
\hline
\end{tabular}

for destinations with highly developed infrastructures, holidays organized through tour operators, and familiar food available at the destination. The overall high safety needs and uncertainty avoidance suggest that risk and uncertainty avoiders are tourists who prefer holidays that are predictable without complications such as those that would be triggered by risk.

The second most risk-averse tourist type, risk avoider, is characterized by very high intentions to revisit familiar destinations with a high safety level, and where safe activities are offered. Risk avoiders moreover prefer preplanned trips in lieu of spontaneous traveling at the destination. In contrast to risk and uncertainty avoiders, risk avoiders prefer to organize their holidays themselves and are more willing to try unfamiliar local food. The choice of safe destinations allows this tourist type to avoid the risk that may arise from the individual holiday organization or the unfamiliar local food.

Two types of novelty-seeking tourists have emerged from the cluster analysis: safe novelty seeker and adventurous novelty seeker. The most distinct features of safe novelty seekers are their preference for new and unfamiliar destinations, unfamiliar local food, and preplanned trips that are often organized by tour operators. This means that while safe novelty seekers desire new experiences at unknown destinations, they are still trying to eliminate risk factors through a well-organized holiday preparation as a strategy to reduce risk and uncertainty factors compensated by a certain type of travel organization. In contrast, adventurous novelty seekers prefer new and unfamiliar destinations where they try local food but tend to largely organize their holidays individually. This individual organization adds a certain level of risk to traveling such as dealing with on-site problems by themselves. An important distinguishing factor of adventurous novelty seekers from their counterpart is the focus on adventurous activities during a holiday.

The most risk-affine tourist type, risk taker, has high values pointing toward risk taking, novelty seeking, and uncertainty acceptance. From all of the tourist types, risk takers have the strongest preference for destinations with less developed infrastructures, and/or safety concerns where they carry out individually organized spontaneous trips without definite routes or timetables. Hence, DCs of risk takers are driven by high risk-taking propensities and novelty-seeking tendencies.

\section{Determinants of the Tourist Typology}

To gain a clearer picture of each tourist type, relations between the tourist typology and tourist characteristics or types of destinations considered during the DC were examined. Table 5 summarizes the results, revealing age, educational level, profession, traveling with young children under the age of six, and travel frequency as significant touristrelated determinants. The low values of Cramér's $V$ show a weak association between significant determinants and the tourist typology. The three investigated stages of DC processes are highly significantly related to the tourist typology. The following sections present the results in more detail, first for variables related to tourist characteristics and second for variables concerning DCs. 
Table 4. Results of the Cluster Analysis for the Tourist Typology.

\begin{tabular}{|c|c|c|c|c|c|}
\hline & $\begin{array}{c}\text { Risk and } \\
\text { Uncertainty } \\
\text { Avoider }\end{array}$ & $\begin{array}{c}\text { Risk } \\
\text { Avoider }\end{array}$ & $\begin{array}{c}\text { Safe } \\
\text { Novelty } \\
\text { Seeker }\end{array}$ & $\begin{array}{c}\text { Adventurous } \\
\text { Novelty } \\
\text { Seeker }\end{array}$ & Risk Taker \\
\hline Total score, ${ }^{\mathrm{a}} \mathrm{M}(\mathrm{SD})$ & $2.37(1.13)$ & $2.62(1.03)$ & $3.09(0.83)$ & $3.54(0.82)$ & $3.9(0.95)$ \\
\hline \multicolumn{6}{|l|}{ Type of destination, $M(S D)$} \\
\hline Familiarity $^{\mathrm{b}}$ & $3.03(1.24)$ & $2.80(1.28)$ & $4.50(0.58)$ & $4.24(0.79)$ & $3.91(1.0)$ \\
\hline (Touristic) infrastructure ${ }^{c}$ & $1.94(1.01)$ & $2.60(1.24)$ & $3.21(0.92)$ & $3.27(1.19)$ & $3.76(0.89)$ \\
\hline Safety $^{d}$ & $2.08(1.13)$ & $1.54(0.84)$ & $2.36(1.03)$ & $2.44(1.02)$ & $3.12(1.15)$ \\
\hline \multicolumn{6}{|l|}{ Type of holiday, M (SD) } \\
\hline Preplanning ${ }^{\mathrm{e}}$ & $1.97(1.14)$ & $1.76(1.10)$ & $1.75(0.70)$ & $1.99(0.82)$ & $4.16(1.03)$ \\
\hline Travel organization ${ }^{f}$ & $2.30(1.14)$ & $4.56(0.76)$ & $2.43(0.92)$ & $4.73(0.47)$ & $4.71(0.61)$ \\
\hline \multicolumn{6}{|l|}{ On-site behaviour, $M(S D)$} \\
\hline Activities $^{g}$ & $2.66(1.14)$ & $1.49(0.63)$ & $2.96(1.07)$ & $3.72(0.70)$ & $3.53(1.10)$ \\
\hline Food $^{\text {h }}$ & $2.62(1.13)$ & $3.54(1.37)$ & $4.43(0.57)$ & $4.35(0.79)$ & $4.19(1.04)$ \\
\hline
\end{tabular}

Note: Values are the mean of reported scores on a 5-point scale. $M=$ mean; SD = standard deviation.

a. Accumulated from scores of the seven items of the cluster analysis; I = strong risk and uncertainty avoidance; $5=$ strong risk and uncertainty affinity.

b. I = revisit of familiar destinations; $5=$ visit of unfamiliar destinations that have not been visited before.

c.I = destinations with highly developed touristic infrastructures; 5 = destinations with less developed touristic infrastructures.

$\mathrm{d} . \mathrm{I}=$ destinations with high levels of safety; 5 = destinations with safety concerns.

e. $I=$ preplanned trips; 5 = trips without definite routes or timetables.

$\mathrm{f} . \mathrm{I}=$ organization through tour operator; 5 = individual independent organization.

g.I = safe activities; 5 = adventurous activities.

h. I = familiar international food; 5 = unfamiliar local food.

Table 5. Results of the Analysis of Relationships Between Tourist Characteristics or Destination Types and the Tourist Typology.

\begin{tabular}{|c|c|c|c|c|c|}
\hline & Significance & df & $\chi^{2}$ & Cramér's V & $r$ \\
\hline \multicolumn{6}{|l|}{ Tourist characteristics } \\
\hline Gender $^{\mathrm{a}}$ & n.s. & 4 & 1.77 & - & - \\
\hline $\mathrm{Age}^{\mathrm{b}}$ & $0.000 * * *$ & - & - & - & -0.231 \\
\hline Educational level $^{\mathrm{a}}$ & $0.000 * * *$ & 16 & 41.31 & 0.166 & - \\
\hline Profession $^{\mathrm{a}}$ & $0.002 * *$ & 28 & 55.22 & 0.191 & - \\
\hline Household income ${ }^{a}$ & n.s. & 40 & 45.61 & - & - \\
\hline Traveling with children under 6 years ${ }^{\mathrm{a}}$ & $0.049 *$ & 4 & 9.55 & 0.326 & - \\
\hline Traveling with children under 14 years ${ }^{\mathrm{a}}$ & n.s. & 4 & 4.13 & - & - \\
\hline Travel frequency ${ }^{\mathrm{b}}$ & $0.000 * * *$ & - & - & - & 0.183 \\
\hline \multicolumn{6}{|l|}{ Destination type } \\
\hline Initial consideration set ${ }^{\mathrm{a}}$ & $0.000 * * *$ & 16 & 50.48 & 0.100 & - \\
\hline Relevant set ${ }^{\mathrm{a}}$ & $0.000 * * *$ & 12 & 42.07 & 0.123 & - \\
\hline Past destination choice ${ }^{\mathrm{a}}$ & $0.000 * * *$ & 16 & 53.50 & 0.098 & - \\
\hline
\end{tabular}

Note: n.s. = not significant.

a. Pearson's chi-squared test.

b. Kruskal-Wallis one-way analysis.

$*_{p}<0.05 ; *_{p}<0.01 ; *^{*} *_{p}<0.001$.

Tourist characteristics. The research question driving the analysis focusing on tourist characteristics is whether tourists with varying attitudes and behaviors toward risk and uncertainty in the travel decision-making process differ in their sociodemographic and travel-related profiles (hypotheses 3-9). Table 6 displays the mean scores for each significant determinant to illustrate their importance for each tourist type, specifically highlighting over- and underrepresentation with an allowance of $10 \%$ variance.
Gender is not a significant influencing factor of the tourist typology. A significant relationship $(p<0.001)$ and negative correlation $(-0.231)$ exists between the age of the respondents and the tourist typology. This means that the older tourists are, the more likely they are assigned to a tourist type that avoids risk and uncertainty while traveling. However, the risk and uncertainty avoider is characterized by an overrepresentation of the age groups between 30 and 59 years, while the age group 60 to 69 years is underrepresented. Moreover, 
Table 6. Scores of Significant Determinants for Each Tourist Type: Focus on Tourist Personality Variables.

\begin{tabular}{|c|c|c|c|c|c|}
\hline & $\begin{array}{c}\text { Risk and Uncertainty } \\
\text { Avoider }\end{array}$ & $\begin{array}{c}\text { Risk } \\
\text { Avoider }\end{array}$ & $\begin{array}{l}\text { Safe Novelty } \\
\text { Seeker }\end{array}$ & $\begin{array}{l}\text { Adventurous } \\
\text { Novelty Seeker }\end{array}$ & Risk Taker \\
\hline Age, years, M (SD) & $38.1(16.3)$ & $43.9(19.1)$ & $41.5(19.9)$ & $30.5(12.2)$ & $31.8(13.6)$ \\
\hline $14-19$ & ${ }^{(-)} 3.5 \%$ & ${ }^{(-)} 2.4 \%$ & ${ }^{(+)} 10.7 \%$ & ${ }^{(+)} 5.1 \%$ & ${ }^{(+)} 5.4 \%$ \\
\hline $20-29$ & $\stackrel{(-)}{(-38.4 \%}$ & (-) $29.8 \%$ & $\stackrel{(-)}{ } 32.1 \%$ & ${ }^{(+)} 57.7 \%$ & ${ }^{(+)} 55.4 \%$ \\
\hline $30-39$ & ${ }^{(+)} 20.9 \%$ & $15.5 \%$ & ${ }^{(-)} 0.0 \%$ & ${ }^{(+)} 19.2 \%$ & $16.1 \%$ \\
\hline $40-49$ & ${ }^{(+)} 11.6 \%$ & ${ }^{(+)} 11.9 \%$ & ${ }^{(+)} 21.4 \%$ & ${ }^{(-)} 6.4 \%$ & ${ }^{(-)} 8.0 \%$ \\
\hline $50-59$ & ${ }^{(+)} 14.0 \%$ & ${ }^{(+)} 11.9 \%$ & $10.7 \%$ & $(-) 9.0 \%$ & $(-) 7.1 \%$ \\
\hline $60-69$ & ${ }^{(-)} 5.8 \%$ & ${ }^{(+)} 14.3 \%$ & ${ }^{(+)} 14.3 \%$ & $(-) \mid .3 \%$ & $7.1 \%$ \\
\hline$>69$ & $5.8 \%$ & ${ }^{(+)} 14.3 \%$ & ${ }^{(+)} 10.7 \%$ & $(-) 1.3 \%$ & ${ }^{(-)} 0.9 \%$ \\
\hline Traveling with children under 6 years & ${ }^{(+)} 54.5 \%$ & ${ }^{(-)} 22.7 \%$ & $(-) 9.1 \%$ & $28.6 \%$ & ${ }^{(-)} 23.8 \%$ \\
\hline \multicolumn{6}{|l|}{ Education } \\
\hline Apprenticeship & $1.3 \%$ & ${ }^{(+)} 3.8 \%$ & ${ }^{(+)} 7.4 \%$ & $(-) 1.3 \%$ & ${ }^{(-)} 0.9 \%$ \\
\hline Junior high school & ${ }^{(+)} 6.4 \%$ & ${ }^{(+)} 6.3 \%$ & ${ }^{(-)} 0.0 \%$ & $(-) 1.3 \%$ & $(-) 1.8 \%$ \\
\hline Secondary school & ${ }^{(+)} 25.6 \%$ & ${ }^{(+)} 23.8 \%$ & ${ }^{(+)} 25.9 \%$ & $\stackrel{(-)}{ } 3.9 \%$ & $\stackrel{(-)}{ } 13.4 \%$ \\
\hline High school & $\stackrel{(-)}{3} 33.3 \%$ & $\stackrel{(-)}{(-23.8 \%}$ & $40.7 \%$ & ${ }^{(+)} 54.5 \%$ & ${ }^{(+)} 47.3 \%$ \\
\hline University or college & $33.3 \%$ & ${ }^{(+)} 42.5 \%$ & $\stackrel{(-)}{ } 25.9 \%$ & $39.0 \%$ & $36.6 \%$ \\
\hline \multicolumn{6}{|l|}{ Profession } \\
\hline Retired & ${ }^{(+)} 10.8 \%$ & ${ }^{(+)} 15.7 \%$ & ${ }^{(+)} 19.2 \%$ & $(-) 1.3 \%$ & $(-) 2.8 \%$ \\
\hline Housewife/husband & ${ }^{(+)} 6.0 \%$ & ${ }^{(+)} 6.0 \%$ & $3.8 \%$ & ${ }^{(-)} \mid .3 \%$ & ${ }^{(-)} \mid .8 \%$ \\
\hline Student & $\stackrel{(-)}{19.3 \%}$ & $16.9 \%$ & $30.8 \%$ & ${ }^{(+)} 44.2 \%$ & ${ }^{(+)} 43.1 \%$ \\
\hline Pupil & ${ }^{(-)} 0.0 \%$ & ${ }^{(+)} 2.4 \%$ & ${ }^{(+)} 3.8 \%$ & ${ }^{(+)} 3.9 \%$ & ${ }^{(-)} \mid .8 \%$ \\
\hline Apprentice & ${ }^{(+)} 7.2 \%$ & $3.6 \%$ & $\stackrel{(-)}{-0.0 \%}$ & ${ }^{(+)} 7.8 \%$ & $(-) 3.7 \%$ \\
\hline Employee, civil servant & ${ }^{(+)} 45.8 \%$ & ${ }^{(+)} 44.6 \%$ & $\stackrel{(-)}{(-26.9 \%}$ & $36.4 \%$ & $36.7 \%$ \\
\hline Self-employed & ${ }^{(+)} 9.6 \%$ & $8.4 \%$ & ${ }^{(+)} 11.5 \%$ & ${ }^{(-)} 3.9 \%$ & $7.3 \%$ \\
\hline Number of trips past three years, $M(S D)$ & $3.1(1.9)$ & $3.7(2.0)$ & $3.1(1.2)$ & $3.9(2.2)$ & $4.1(2.3)$ \\
\hline
\end{tabular}

Note: Over- or underrepresented groups are included in case of more than $10 \%$ variance. SD = standard deviation; $(+)=$ overrepresented; $(-)=$ underrepresented.

in the safe novelty seeker tourist type, young and old age groups are overrepresented, while the age groups between 20 and 39 years are underrepresented. Profession and educational level are both significantly related to the tourist typology $(p<0.01, p<0.001)$. Students and high school degrees are overrepresented in tourist types with higher risk affinities and underrepresented in less risk- or uncertainty-affine tourist types. The group of pensioners and retirees is overrepresented in the two least risk-affine tourist types. Although educational level or profession are in many cases linked to the level of income, household income is not significantly related to the tourist typology. Hence, only hypotheses 4, 5, and 6 are accepted as the sociodemographic variables age, educational level, and profession are related to tourists' attitudes and behaviors toward risk and uncertainty in travel decision-making.

A significant relation $(p<0.05)$ was found between the travel-related variable traveling with children under the age of 6 and the tourist typology. In particular, risk and uncertainty avoiders are more likely to travel with young children under the age of 6 . However, traveling with children seems only relevant for young children, because no significant relation was detected between the tourist typology and traveling with children under the age of 14. Consequently, hypothesis
8 can be accepted only for tourists traveling with young children. Travel frequency (i.e., number of main holidays in the past three years) as a proxy for travel experience is also a significant travel-related determinant of the tourist typology $(p<0.001)$ with a positive correlation (.183) between number of holidays and the tourist typology, which confirms hypothesis 9 . The more holidays have been realized, the more likely tourists are categorized into tourist types with higher risktaking propensities and lower risk and uncertainty avoidances. Accordingly, risk takers have the highest (4.1 trips per three years) and risk and uncertainty avoiders the lowest travel frequency (3.1 trips per three years). Safe novelty seekers also have a very low travel frequency, with 3.1 trips in the last three years.

Destination choice. The research question leading the analysis focusing on the DC and destination characteristics is: In which way do tourist types vary concerning the type of destination that is considered at different stages of the DC process? In each examined DC set, the type of destination according to the destination index (Table 2 ) is significantly related to the tourist typology $(p<0.001)$, and hypothesis 1 and 2 are therefore accepted. Table 7 displays the mean percentages for each tourist type as well as over- and 
Table 7. Scores of Significant Determinants for Each Tourist Type: Focus on Destination Choice Variables.

\begin{tabular}{|c|c|c|c|c|c|c|}
\hline & $\begin{array}{c}\text { Risk and } \\
\text { Uncertainty } \\
\text { Avoider }\end{array}$ & $\begin{array}{c}\text { Risk } \\
\text { Avoider }\end{array}$ & $\begin{array}{l}\text { Safe } \\
\text { Novelty } \\
\text { Seeker }\end{array}$ & $\begin{array}{l}\text { Adventurous } \\
\text { Novelty } \\
\text { Seeker }\end{array}$ & $\begin{array}{l}\text { Risk } \\
\text { Taker }\end{array}$ & Average \\
\hline \multicolumn{7}{|l|}{ Initial consideration set } \\
\hline Easy travel & $38.2 \%$ & ${ }^{(+)} 47.2 \%$ & $37.8 \%$ & (-) $24.4 \%$ & $32.9 \%$ & $36.1 \%$ \\
\hline Out-of-the-ordinary & ${ }^{(-)} 5.9 \%$ & ${ }^{(+)} 11.0 \%$ & ${ }^{(+)} 12.2 \%$ & ${ }^{(+)} 13.6 \%$ & $9.3 \%$ & $10.4 \%$ \\
\hline Safe adventure & $36.5 \%$ & ${ }^{(-)} 29.1 \%$ & ${ }^{(-)} 28.6 \%$ & $35.3 \%$ & $34.6 \%$ & $32.8 \%$ \\
\hline Tricky discovery & $19.4 \%$ & $\stackrel{(-)}{ } 12.6 \%$ & $21.4 \%$ & ${ }^{(+)} 26.4 \%$ & $22.4 \%$ & $20.4 \%$ \\
\hline No go & ${ }^{(-)} 0.0 \%$ & ${ }^{(-)} 0.0 \%$ & ${ }^{(-)} 0.0 \%$ & ${ }^{(+)} 0.4 \%$ & ${ }^{(+)} 0.8 \%$ & $0.2 \%$ \\
\hline \multicolumn{7}{|l|}{ Relevant set } \\
\hline Easy travel & $75.1 \%$ & $80.0 \%$ & $73.0 \%$ & $76.7 \%$ & ${ }^{(-)} 63.7 \%$ & $73.7 \%$ \\
\hline Out-of-the-ordinary & ${ }^{(+)} 13.7 \%$ & $9.5 \%$ & ${ }^{(-)} 8.1 \%$ & ${ }^{(-)} 6.2 \%$ & $9.0 \%$ & $9.3 \%$ \\
\hline Safe adventure & ${ }^{(-)} 6.1 \%$ & ${ }^{(-)} 6.5 \%$ & ${ }^{(+)} 9.5 \%$ & (+) $9.3 \%$ & ${ }^{(+)} 10.5 \%$ & $8.4 \%$ \\
\hline Tricky discovery & ${ }^{(-)} 5.1 \%$ & ${ }^{(-)} 4.0 \%$ & $9.5 \%$ & ${ }^{(-)} 7.8 \%$ & ${ }^{(+)} 16.9 \%$ & $8.7 \%$ \\
\hline No go & $0.0 \%$ & $0.0 \%$ & $0.0 \%$ & $0.0 \%$ & $0.0 \%$ & $0 \%$ \\
\hline \multicolumn{7}{|l|}{ Past destination choice } \\
\hline Easy travel & $77.7 \%$ & $81.8 \%$ & $75.3 \%$ & $80.5 \%$ & $72.7 \%$ & $77.6 \%$ \\
\hline Out-of-the-ordinary & ${ }^{(+)} 13.5 \%$ & $9.1 \%$ & ${ }^{(+)} \mid 1.8 \%$ & ${ }^{(-)} 6.6 \%$ & $8.0 \%$ & $9.8 \%$ \\
\hline Safe adventure & ${ }^{(-)} 5.0 \%$ & ${ }^{(-)} 5.5 \%$ & ${ }^{(-)} 2.4 \%$ & $6.6 \%$ & ${ }^{(+)} 8.0 \%$ & $5.5 \%$ \\
\hline Tricky discovery & $(-) 3.8 \%$ & $(-) 3.6 \%$ & (+) $9.4 \%$ & $6.3 \%$ & ${ }^{(+)} \mid 1.3 \%$ & $6.9 \%$ \\
\hline No go & ${ }^{(-)} 0.0 \%$ & ${ }^{(-)} 0.0 \%$ & ${ }^{(+)} 1.2 \%$ & ${ }^{(-)} 0.0 \%$ & ${ }^{(-)} 0.0 \%$ & $0.2 \%$ \\
\hline
\end{tabular}

Note: Over- or underrepresented groups are included in case of more than $10 \%$ variance. $(+)=$ overrepresented; $(-)=$ underrepresented.

underrepresented destination categories to illustrate the DC sets according to the destination index.

In the initial consideration set, easy travel destinations are the largest group of destinations $(24.4 \%$ to $47.2 \%$ of all destinations in this set), in particular concerning the risk avoider (47.2\%, overrepresented). The second most important destination category is safe adventure, with values ranging from $28.6 \%$ for safe novelty seekers to $36.5 \%$ for risk and uncertainty avoiders. Destinations in the tricky discovery category range from $12.6 \%$ (risk avoider) to $26.4 \%$ (adventurous novelty seeker), while out-of-the-ordinary destinations range from $5.9 \%$ (risk and uncertainty avoider) to $13.6 \%$ (adventurous novelty seeker). Out-of-the-ordinary destinations are overrepresented in the initial consideration set for risk avoiders, safe novelty seekers, and adventurous novelty seekers. No go destinations are only present in the initial consideration set of the two most risk-taking tourist types, adventurous novelty seeker and risk taker.

The more realistic DC sets, relevant set and past DCs, have a similar structure with regards to the type of considered destination (e.g., domination of easy travel destinations). The relevant set of the least risk-taking tourist types (i.e., risk and uncertainty avoider, risk avoider) are notably dominated by destinations from the easy travel category $(75.1 \%, 80.0 \%)$ but lack long-haul destinations of the safe adventure and tricky discovery categories (underrepresented), whereas the easy travel category is underrepresented in the risk taker tourist type (63.7\%). Safe adventure destinations are more relevant for both novelty-seeking and the risk taker tourists $(9.5 \%, 9.3 \%, 10.5 \%$, overrepresented), while tricky discovery destinations are mainly relevant for risk takers $(16.9 \%$, overrepresented). Out-of-the-ordinary destinations are an important category for risk and uncertainty avoiders (13.7\%, overrepresented) and less relevant for the other tourist types. Safe novelty seekers are the only tourists who traveled to a destination from the no go category in the past three years.

While Pearson's chi-squared test is able to show that there is variability in the type of considered destination between the tourist types, it is not able to give information on the amount of this variance. To see whether differences are stronger between the tourist types among the destinations in the initial consideration set, the relevant set or past DCs, deviations in the structure of each set were calculated for each tourist type. In this study, deviation is defined as the variance of one tourist type from the average share of a destination category in a DC set for all tourist types (Formula 1). Deviation is measured as difference from the average in percentage points (pp). Because of the bias in the sample, deviation is not calculated from the total percentage distribution over all cases but the average percentage distribution based on the means of the five tourist types. For example, a positive deviation value for the easy travel destination category in the relevant set means that a tourist type considers more destinations from the easy travel category in this DC set than the average of all tourist types.

$$
\operatorname{deviation}\left(i_{n}\right)=\left(\sum_{n=1}^{5} i_{n} / 5\right)-i_{n}
$$


where $i=$ category of destination index; $n=$ tourist type.

Deviation is measured as difference from the average in percentage points. For example, a positive deviation value for the easy travel destination category in the relevant set means that a tourist type considers more destinations from the easy travel category in this DC set than the average of all tourist types. Table 8 displays the results of the calculation of deviations in the DC structure.

Among the tourist types, risk avoiders and adventurous novelty seekers show the strongest deviation in the initial consideration set $(23.5 \mathrm{pp})$ resulting from differences concerning the easy travel category. Risk avoiders consider more $(+11.1 \mathrm{pp})$ and adventurous novelty seekers less $(-11.7 \mathrm{pp})$ destinations from the easy travel category. The tourist types closest to the average are the safe novelty seeker and risk taker with a low sum of deviations (8.9/8.6 pp). In the relevant set, risk takers differ most from the average (20.7 pp), particularly in the easy travel $(-10 \mathrm{pp})$ and tricky discovery $(+8.2 \mathrm{pp})$ category. The relevant set structure of the safe novelty seeker is the least deviant (3.9 pp). In the past DCs, the strongest deviation is found for the risk taker (13.9 pp) with more destinations in the tricky discovery $(-4.4 \mathrm{pp})$ and less in the easy travel $(-4.9 \mathrm{pp})$ category. The structure of past destination choices of risk and uncertainty avoiders (7.6 pp), risk avoiders ( $8.4 \mathrm{pp})$, and adventurous novelty seekers $(8.0$ pp) are rather average. For a comparison of deviations between the initial consideration set, relevant set, and past DC, regardless of the orientation of the variance, the sums of absolute deviations were calculated for each DC segment (Table 8). These absolute sums reveal that the differences between the five tourist types are stronger in the initial consideration set $(76.1 \mathrm{pp})$ than in the relevant set $(57.1 \mathrm{pp})$ and past DCs (48.8 pp).

\section{Discussion}

Comparisons between this study's results and past research are generally difficult because of the nature of combining multiple aspects associated with risk in travel decisions, whereas most studies and research focus on only one aspect. Because of this design, implications can be drawn partly from studies on risk perception.

\section{Tourist Characteristics}

Focusing on tourist characteristics, determinants that explain differences in the way risk and uncertainty are treated in travel decision-making include age, educational level, and profession as sociodemographic variables, as well as travelrelated variables such as traveling with young children and past travel experience. Research on the influence of gender and age on risk perception is contradictory and inconsistent, which may result from the variety in research designs and data collection methodologies. No significant relation for both factors is found in studies by Sönmez and Graefe (1998a, 1998b) while Reisinger and Mavondo (2006) detect a significant relation for some subcategories of risk perception. Lepp and Gibson (2008) find that gender is only significant for subcategories of risk that may disrupt a holiday (i.e., strangeness of food) but not for life-threatening risk factors. Pizam et al. (2004) investigated not only risk perception but also behavior and evaluation of risk and found that gender, but not age, is an influencing factor. The discrepancy of this study's results could be explained by the focus on one age group since age differences are most likely clearer over the whole span of ages. Furthermore, a study by Hajibaba et al. (2015) demonstrates how in particular tourists who are extremely resistant to risk with high risk-taking propensities are generally younger than other tourists with a more riskaverse behavior. The significant relation between the variables profession as well as educational level and the tourist typology corroborate past studies that show that education is negatively correlated to risk perception (Park and Reisinger 2010; Sönmez and Graefe 1998a), and higher levels of education lead to a lower perception of the influencing power of risk on travel intentions (Park and Reisinger 2010). Park and Reisinger's $(2010,19)$ explanation is that "tourists with low educational attainment perceive a greater influence of social risk than high- and middle-educated tourists perhaps because they have relatively less social skills and are less confident about their vacation choice."

The outstanding position of the age group 30 to 39 years in the risk and uncertainty avoider tourist type, contradicting a negative correlation between age and risk perception, may result from particular circumstances that influence travel decision-making. This tourist type is more likely to travel with (young) children among all tourist types, which needs to be incorporated in travel decision-making resulting in likely decisions toward less risk and uncertainty. Furthermore, the results of this study reveal that traveling with young children (under the age of six) along with tourists' attitudes and behaviors toward risk and uncertainty in travel decisionmaking are significantly related, while traveling with children under the age of 14 is not significantly related. This reaffirms a study by Roehl and Fesenmaier (1992), who state that tourists who focus on specific organizational risk are more often traveling with young children than other tourists. Furthermore, the family situation has been identified as a strong constraining factor of DCs deterring tourists from implementing hypothetical holidays (Karl, Reintinger, and Schmude 2015). Another significant characteristic of the tourist typology with regard to age is the large share of the youngest age group among safe novelty seekers. One explanation may be that these respondents are still at the beginning of their travel career. Consequently, they have not yet achieved sufficient travel experience that would allow them to feel confident traveling to more difficult or risky destinations. The concept of tourist knowledge helps explain why travel experience influences risk perception. The results of studies conducted by Sharifpour and colleagues (Sharifpour, 
Table 8. Deviation in the DC Structure between Tourist Types and DC Sets.

\begin{tabular}{|c|c|c|c|c|c|c|}
\hline & $\begin{array}{c}\text { Risk and } \\
\text { Uncertainty } \\
\text { Avoider }\end{array}$ & $\begin{array}{c}\text { Risk } \\
\text { Avoider }\end{array}$ & $\begin{array}{l}\text { Safe Novelty } \\
\text { Seeker }\end{array}$ & $\begin{array}{c}\text { Adventurous } \\
\text { Novelty } \\
\text { Seeker }\end{array}$ & $\begin{array}{l}\text { Risk } \\
\text { Taker }\end{array}$ & $\sum \mid$ deviation $\mid$ \\
\hline \multicolumn{7}{|l|}{ Initial consideration set } \\
\hline Easy travel & 2.1 & II.1 & 1.7 & -11.7 & -3.2 & 29.8 \\
\hline Out-of-the-ordinary & -4.5 & 0.6 & 1.8 & 3.2 & -1.1 & 11.2 \\
\hline Safe adventure & 3.7 & -3.7 & -4.2 & 2.5 & 1.8 & 15.9 \\
\hline Tricky discovery & -1.0 & -7.8 & 1.0 & 6.0 & 2.0 & 17.8 \\
\hline No go & -0.2 & -0.2 & -0.2 & 0.2 & 0.6 & 1.4 \\
\hline$\sum \mid$ deviation $\mid$ & 11.6 & 23.5 & 8.9 & 23.5 & 8.6 & 76.1 \\
\hline \multicolumn{7}{|l|}{ Relevant set } \\
\hline Easy travel & $\mathrm{I} .4$ & 6.3 & -0.7 & 3 & -10 & 21.4 \\
\hline Out-of-the-ordinary & 4.4 & 0.2 & -1.2 & -3.1 & -0.3 & 9.2 \\
\hline Safe adventure & -2.3 & -1.9 & I.I & 0.9 & 2.1 & 8.3 \\
\hline Tricky discovery & -3.6 & -4.7 & 0.8 & -0.9 & 8.2 & 18.2 \\
\hline No go & 0 & 0 & 0 & 0 & 0 & 0 \\
\hline$\sum \mid$ deviation| & 11.6 & 13.0 & 3.9 & 7.9 & 20.7 & 57.1 \\
\hline \multicolumn{7}{|l|}{ Past destination choice } \\
\hline Easy travel & 0.1 & 4.2 & -2.3 & 2.9 & -4.9 & 14.4 \\
\hline Out-of-the-ordinary & 3.7 & -0.7 & 2 & -3.2 & -1.8 & 11.4 \\
\hline Safe adventure & -0.5 & 0 & -3.1 & I.I & 2.5 & 7.2 \\
\hline Tricky discovery & -3.1 & -3.3 & 2.5 & -0.6 & 4.4 & 13.9 \\
\hline No go & -0.2 & -0.2 & 1.0 & -0.2 & -0.2 & 1.9 \\
\hline$\sum \mid$ deviation $\mid$ & 7.6 & 8.4 & 10.9 & 8.0 & 13.9 & 48.8 \\
\hline
\end{tabular}

Note: Values represent deviation from the average in percentage points.

Walters, and Ritchie 2014; Sharifpour et al. 2014) indicate that an increased subjective knowledge, such as self-confidence in one's knowledge, reduces the level of perceived risk, while objective or actual knowledge has no significant influence on risk perception. The significant but weak correlation between the tourist typology and the travel frequency may be caused by the relatively small size of the data set (n =402). However, conclusions that are drawn from the positive trend are confirmed by former studies on risk perception where tourists with great (international) travel experience have a lower general risk perception (Fuchs and Reichel 2011; Sönmez and Graefe 1998a, 1998b), or at least lower risk perceptions regarding certain dimensions (Rittichainuwat and Chakraborty 2009). Additionally, Floyd et al. (2004, 32) found travel experience to be "the most significant predictor of travel intentions". A study by Hajibaba et al. $(2015,49)$ on crisis-resistant tourists who are known to accept higher levels of risk and "tend to absorb risks instead of engaging in risk avoidance strategies" reaches similar conclusions: A particular characteristic of crisis-resistant tourists relates to the wide experiences of international travel.

\section{Destination Choice}

Our analysis of tourists' DCs indicates that the way tourists perceive risk and uncertainty in travel decision-making and DCs are interrelated. Tourists with risk aversion tendencies consider and visit well-known, highly developed destinations with strong tourist flows from the source market, resulting in a high level of familiarity and low level of uncertainty. Tourists with higher risk affinities consider destinations with lower travel intensities, weaker tourism flows from the source market, and hence lower levels of familiarity for future holidays. These tourists also either plan to travel or have traveled to such types of destinations or "easy travel" destinations. Using a combination of several items referring to risk and uncertainty in a tourist typology, this study confirms and enhances studies on risk, uncertainty, familiarity, or sensation seeking in travel decision-making. However, comparisons to past studies are limited as few studies integrate destination as well as tourist attributes.

One example can be seen in the study conducted by Roehl and Fesenmaier (1992) on risk perceptions and pleasure travel discussing destination attributes as an explanatory factor. Their division of tourists according to risk perception results in three types of tourists: risk-neutral tourists with a low level of perceived risk and risky travel behavior; functional-risk tourists with a strong perception of specific organizational risk; and place-risk tourists with a high level of perceived risk and familiarity-seeking travel behavior. In a further study, Lo, Law, and Cheung (2011) develop a segmentation of tourists according to their risk reduction strategies and integrate the travel destination as one variable: one group of tourists relies on others for risk reduction (e.g., 
seeking advice from friends/relatives), while a second group of tourists reduces risks by themselves (e.g., purchasing travel insurance); a third group of tourists does not feel the need to reduce risks. However, actual DC processes or a broad range of destination characteristics are not explicitly investigated.

This study was able to verify and enhance Roehl and Fesenmaier's (1992) tourist typology by investigating different stages of the DC process with actual destination attributes. Risk avoiders are equal to place-risk tourists as all stages of DC are dominated by safe destinations that are highly familiar to German tourists. Risk takers represent the opposite end of the scale since they consider comparatively few easy travel destinations and more difficult destinations with higher levels of risk and less familiarity. Risk takers can be seen as equal to Roehl and Fesenmaier's (1992) risk-neutral tourist who is not discouraged to travel to certain destinations because of risk as well as Lo, Law, and Cheung's (2011) tourist type who is not concerned by any risks and travels mostly internationally. It seems plausible that for them risk is not an obstacle but an asset for traveling, as suggested by Adam (2015). From the tourist perspective, risk and uncertainty avoiders have been identified as functional-risk tourists because of family situations complicating their travel plans. From the destination perspective, both risk and uncertainty avoiders and safe novelty seekers may be equivalent to Roehl and Fesenmaier's (1992) functional-risk tourists. Both tourist types initially consider many long-haul destinations that are safe and novel to some degree, but travel to familiar safe short-haul destinations and less common safe destinations at a medium distance. Organizational risks that may occur while traveling are reduced either by the choice of destination (i.e., risk and uncertainty avoiders prefer safe destinations) or the kind of travel organization (i.e., safe novelty seekers prefer traveling with tour operators).

The closer examination of deviations in the DC structures shows that the total amount of deviation from the average DC structure decreases and that differences between the tourist types in regard to the types of considered destinations become less apparent from hypothetical future (initial consideration set) to realistically planned (relevant set) to actually executed (past DC) DCs. This implies that tourists with varying attitudes and perceptions of risk and uncertainty dream of different types of destinations, but decide rather similarly when it comes to actually choosing a destination. One explanation can be taken from the concept of facilitators and inhibitors (positive or negative destination attributes) in travel decision-making. Um and Crompton (1992) demonstrate how inhibitors take on greater significance by the end of the DC process while facilitators are more relevant at the beginning. Combining Um and Crompton's (1992) results with the observations from this study, the assumption is that destination attributes, which tourists are attracted to, are rather different, while travel constraints, which deter tourists from traveling to destinations, are more alike, leading to a greater similarity in patterns of actual DCs. Crawford, Jackson, and Godbey's (1991) hierarchical model of leisure constraints can be consulted to understand this result. Risk and uncertainty affinity can be seen as intrapersonal constraints which are the strongest travel constraints (Chen, Chen, and Okumus 2013), particularly at the beginning of the choice process (Crawford, Jackson, and Godbey 1991). Tourists with high risk and uncertainty avoidance already reject less familiar destinations and do not even consider them for hypothetical future holidays. Later on, the choice process is dominated by interpersonal constraints and then structural constraints such as financial or time limitations, which are the most common travel constraints during the transition from hypothetical to actual DCs (Karl, Reintinger, and Schmude 2015). Here, risk plays a less important role since most destinations without financial or time limitations are located in proximity and in case of Germany are not associated with safety or security risks.

The application of a tourist and destination perspective allows furthermore understanding the decreasing deviation between tourist types from hypothetical to realistic DCs. At the beginning of the DC process, represented by the hypothetical initial consideration set, such travel constraints are ignored in many cases and therefore tourists include destinations in this set that are not realizable in the end. Later when it comes to actually choosing a destination, travel constraints have to be considered and destinations associated with such constraints are eliminated. Moreover, Nyaupane and Andereck (2008) show that travel constraints are also linked to tourists' characteristics and tourists perceive constraints differently depending on factors such as age or gender, and maybe risk affinity as well. While risk-affine and noveltyseeking tourists dream of rather "difficult" destinations, riskaverse tourists already reject these kinds of destinations before the formation of the initial consideration set. This implies that risk and uncertainty can influence the DC process at different times depending on the tourists' affinity toward risk and uncertainty.

\section{Conclusion}

\section{Theoretical Implications}

While research on risk and uncertainty as a determinant of DC focuses on specific factors in a more isolated way, this study combines several aspects (uncertainty avoidance, sensation seeking, novelty seeking, and risk-taking propensity) to develop a comprehensive tourist typology of travel decision-making. Furthermore, it includes destination attributes in form of a destination index that is based on objective indicators for a destination's level of familiarity and (un)certainty (Karl, Reintinger, and Schmude 2015). The integrated research approach, including self-assessment of travel decision-making, and actual DC behavior, leads to a better understanding of tourists' personalities, travel behaviors, and DC 
under the influence of risk and uncertainty. This study further demonstrates that tourists' attributes and behaviors toward risk and uncertainty in travel decision-making is reflected in the DC process. In many cases, self-assessments of noveltyseeking tendencies are only applicable to hypothetical scenarios because the actual DCs do not reflect the selfassessments, underlining the necessity to distinguish between self-assessment and actual behavior. Another benefit of this study is that it not only focuses on hypothetical (e.g., Sarman, Scagnolari, and Maggi 2016; Sharifpour et al. 2014) or actual (e.g., Decrop 2010) choices but rather on ideal, planned, and actual DCs. By using this approach, this study is able to analyze discrepancies between choices that are more or less realistically implemented. The results show that tourists with varying attitudes and behaviors toward risk and uncertainty differ strongly with their hypothetical DCs and are rather similar when it comes to actual implemented DCs. This finding emphasizes that the influence of risk and uncertainty on DCs cannot only be deduced from observable travel behavior or hypothetical travel wishes, and tourism research should focus on both aspects as risk perception often becomes apparent through the consideration of discrepancies between them.

\section{Managerial Implications}

A better understanding of the interaction between tourist and destination attributes during the DC process is of relevance for the marketing and management of destinations with negative safety and security associations. This study's results can help in creating more differentiated marketing and advertisement for types of tourists varying not only by sociodemographic variables but also by risk and uncertainty affinities. The latent demand caused by the lack of implementation of travel wishes could be a promising factor for various destinations, particularly if destinations are rejected during the DC process due to inordinate risk perceptions that do not reflect the actual situation. The destination Crete has approached this problem by launching a promotional video that directly addresses the discrepancy between the actual and perceived situation after the economic crisis in Greece. Another strategy is seen with the promotion of group tours with specially trained tour guides that partly transfers the responsibility for tourists' safety to the tour operator, thereby reducing the level of perceived risk and uncertainty for the tourist. An interesting example are adventurous novelty seekers, where the analysis of actually considered destinations reveals a strong discrepancy between the more realistic (relevant set, and past DC) and hypothetical (initial consideration set) DC. The relatively low mean age of this tourist type indicates that adventurous novelty seekers are still at the beginning of their travel career. Consequently, they may not have enough travel experience and self-confidence in their travels to implement their hypothetical travel plans. Inexperienced tourists can cautiously approach more and more "difficult" destinations and gradually approach their dream destinations. Specific travel programs geared toward young travelers with some degree of guidance to help with difficulties while traveling (e.g., bilingual tour guide to overcome language barriers) could be a solution to eliminate this discrepancy at an earlier time. Another promoting factor could be the use of peers in marketing strategies specifically addressing common travel issues, and risk or uncertainty aspects. If young travelers are presented with the image that their peers travel to a "difficult" destination, they might decide to imitate such behavior and also choose this destination for their next holiday.

\section{Limitations and Further Research}

Some factors that have been integrated in the tourist typology are influenced by the nationality or cultural background of the respondents (e.g., uncertainty avoidance, Kozak, Crotts, and Law 2007; risk perception, Seabra et al. 2013; sensation seeking and risk-taking propensity, Pizam et al. 2004). Therefore, a limitation of this study is the transferability and generalization of these results. This study serves as an explorative case focusing on German tourists impeding the direct application of research results on other markets with different cultural characteristics. The results should be understood considering the generally high uncertainty avoidance (Hofstede, Hofstede, and Minkov 2010) and high travel experience (Lohmann, Schmücker, and Sonntag 2014) of Germans. Intercultural aspects, in particular concerning risk, should be addressed in future research to the degree to which tourists are accustomed to certain types or levels of risk from their home country will most likely play a role in the perception, attitudes, or behavior toward risk while traveling.

\section{Declaration of Conflicting Interests}

The author declared no potential conflicts of interest with respect to the research, authorship, and/or publication of this article.

\section{Funding}

The author disclosed receipt of the following financial support for the research, authorship, and/or publication of this article: This work was supported by the German Research Foundation (DFG) under Grant SCHM 850 / 20-1.

\section{References}

Adam, I. 2015. 'Backpackers' Risk Perceptions and Risk Reduction Strategies in Ghana.” Tourism Management 49:99-108.

Ankomah, P. K., J. L. Crompton, and D. Baker. 1996. "Influence of Cognitive Distance in Vacation Choice." Annals of Tourism Research 23 (1): 138-50.

Bandura, A. 1977. "Self-Efficacy: Toward a Unifying Theory of Behavioral Change." Psychological Review 84 (2): 191-215.

Bekk, M., M. Sporrle, and J. Kruse. 2015. "The Benefits of Similarity between Tourist and Destination Personality." Journal of Travel Research. Published online October 7. doi: 10.1177/0047287515606813. 
Butler, R. W. 2012. "Tourism Geographies or Geographies of Tourism. Where the Bloody Hell Are We?" In The Routledge Handbook of Tourism Geographies, edited by J. Wilson, 2634. London: Routledge.

Chen, H.-J., P.-J. Chen, and F. Okumus. 2013. "The Relationship between Travel Constraints and Destination Image. A Case Study of Brunei." Tourism Management 35:198-208.

Cohen, E. 1972. "Toward a Sociology of International Tourism." Social Research 39 (1): 164-182.

Crawford, D., E. Jackson, and G. Godbey. 1991. "A Hierarchical Model of Leisure Constraints." Leisure Sciences 13 (4): 309-20.

Crompton, J. L. 1992. "Structure of Vacation Destination Choice Sets." Annals of Tourism Research 19 (3): 420-34.

Crompton, J. L., and P. K. Ankomah. 1993. "Choice Set Propositions in Destination Decisions." Annals of Tourism Research 20 (3): 461-76.

Crouch, G. I., T. Huybers, and H. Oppewal. 2016. "Inferring Future Vacation Experience Preference from Past Vacation Choice: A Latent Class Analysis." Journal of Travel Research 55 (5): 574-87.

Decrop, A. 2006. Vacation Decision-making. Wallingford, UK: CABI.

Decrop, A. 2010. "Destination Choice Sets: An Inductive Longitudinal Approach." Annals of Tourism Research 37 (1): 93-115.

Drakos, K., and A. M. Kutan. 2003. "Regional Effects of Terrorism on Tourism in Three Mediterranean Countries." Journal of Conflict Resolution 47 (5): 621-41.

Fletcher, J., and Y. Morakabati. 2008. "Tourism Activity, Terrorism and Political Instability within the Commonwealth: The Cases of Fiji and Kenya." International Journal of Tourism Research 10 (6): 537-56.

Floyd, M. F., H. Gibson, L. Pennington-Gray, and B. Thapa. 2004. "The Effect of Risk Perceptions on Intentions to Travel in the Aftermath of September 11, 2001." Journal of Travel \& Tourism Marketing 15 (2/3): 19-38.

Fuchs, G. 2013. "Low versus High Sensation-Seeking Tourists: A Study of Backpackers' Experience Risk Perception." International Journal of Tourism Research 15 (1): 81-92.

Fuchs, G., and A. Reichel. 2006. "Tourist Destination Risk Perception: The Case of Israel." Journal of Hospitality \& Leisure Marketing 14 (2): 83-108.

Fuchs, G., and A. Reichel. 2011. "An Exploratory Inquiry into Destination Risk Perceptions and Risk Reduction Strategies of First Time vs. Repeat Visitors to a Highly Volatile Destination." Tourism Management 32 (2): 266-76.

Fuchs, G., N. Uriely, A. Reichel, and D. Maoz. 2013. "Vacationing in a Terror-Stricken Destination: Tourists' Risk Perceptions and Rationalizations." Journal of Travel Research 52 (2): 182-91.

Fyall, A. 2013. "Destinations.” In Tourism. Principles and Practice, edited by J. Fletcher, A. Fyall, D. Gilbert, and S. Wanhill, 117143. Harlow: Pearson Education.

Gray, J. M., and M. A. Wilson. 2009. "The Relative Risk Perception of Travel Hazards." Environment and Behavior 41 (2): 185-204.

Hajibaba, H., U. Gretzel, F. Leisch, and S. Dolnicar. 2015. "Crisisresistant Tourists." Annals of Tourism Research 53:46-60.

Hall, C. M., and V. O'Sullivan. 1996. "Tourism, Political Instability and Violence." In Tourism, Crime and International
Security Issues, edited by A. Pizam and Y. Mansfeld, 105-21. Chichester, UK: Wiley.

Hofstede, G., G. Hofstede, and M. Minkov. 2010. Cultures and Organizations: Software of the Mind. New York: McGrawHill.

IEP (Institute for Economics and Peace). 2013. "Global Peace Index." http://www.visionofhumanity.org/\#page/indexes/global-peaceindex/2013 (accessed May 26, 2014).

Jackson, D. N., L. Hourany, and N. J. Vidmar. 1972. "A FourDimensional Interpretation of Risk Taking." Journal of Personality 40 (3): 483-501.

Jonas, A., Y. Mansfeld, S. Paz, and I. Potasman. 2011. "Determinants of Health Risk Perception among Low-RiskTaking Tourists Traveling to Developing Countries." Journal of Travel Research 50 (1): 87-99.

Karl, M., C. Reintinger, and J. Schmude. 2015. "Reject or Select: Mapping Destination Choice." Annals of Tourism Research 54:48-64.

Kozak, M., J. C. Crotts, and R. Law. 2007. "The Impact of the Perception of Risk on International Travellers." International Journal of Tourism Research 9 (4): 233-42.

Larsen, S., W. Brun, T. Øgaard, and L. Selstad. 2007. "Subjective Food-Risk Judgements in Tourists." Tourism Management 28 (6): 1555-59.

Lee, T. H., and C. H. Tseng. 2015. "How Personality and Risk-Taking Attitude Affect the Behavior of Adventure Recreationists." Tourism Geographies 17 (3): 307-31.

Lepp, A., and H. Gibson. 2003. "Tourist Roles, Perceived Risk and International Tourism." Annals of Tourism Research 30 (3): 606-24.

Lepp, A., and H. Gibson. 2008. "Sensation Seeking and Tourism: Tourist Role, Perception of Risk and Destination Choice." Tourism Management 29 (4): 740-50.

Lo, A., C. Cheung, and R. Law. 2011. "Hong Kong Residents' Adoption of Risk Reduction Strategies in Leisure Travel." Journal of Travel \& Tourism Marketing 28 (3): 240-60.

Lo, A., R. Law, and C. Cheung. 2011. "Segmenting Leisure Travelers by Risk Reduction Strategies." Journal of Travel \& Tourism Marketing 28 (8): 828-39.

Lohmann, M., D. Schmücker, and U. Sonntag. 2014. German Holiday Travel 2025: Development of Holiday Travel Demand in the German Source Market (The Reiseanalyse trend analysis). Kiel: F.U.R.

Mansfeld, Y. 2006. "The Role of Security Information in Tourism Crisis Management: The Missing Link.” In Tourism, Security and Safety: From Theory to Practice, edited by Y. Mansfeld and A. Pizam, 271-90. Amsterdam: Elsevier ButterworthHeinemann.

Morakabati, Y., and G. Kapuściński. 2016. "Personality, Risk Perception, Benefit Sought and Terrorism Effect." International Journal of Tourism Research.

Mowen, J. C., and M. Minor. 2001. Consumer Behavior: A Framework. Upper Saddle River, NJ: Prentice Hall.

Nyaupane, G. P., and K. L. Andereck. 2008. "Understanding Travel Constraints: Application and Extension of a Leisure Constraints Model." Journal of Travel Research 46 (4): 433-39.

Park, K., and Y. Reisinger. 2010. "Differences in the Perceived Influence of Natural Disasters and Travel Risk on International Travel." Tourism Geographies 12 (1): 1-24. 
Pizam, A., G.-H. Jeong, A. Reichel, H. van Boemmel, J. M. Lusson, L. Steynberg, O. State-Costache, S. Volo, C. Kroesbacher, J. Kucerova, and N. Montmany. 2004. "The Relationship between Risk-Taking, Sensation-Seeking, and the Tourist Behavior of Young Adults: A Cross-Cultural Study." Journal of Travel Research 42 (3): 251-60.

Plog, S. C. 1974. "Why Destination Areas Rise and Fall in Popularity." Cornell Hotel and Restaurant Administration Quarterly 14 (4): 55-58.

Plog, S. C. 2001. "Why Destination Areas Rise and Fall in Popularity: An Update of a Cornell Quarterly Classic." Cornell Hotel and Restaurant Administration Quarterly 42 (3): 13-24.

Quintal, V. A., J. A. Lee, and G. N. Soutar. 2010. "Risk, Uncertainty and the Theory of Planned Behavior: A Tourism Example." Tourism Management 31 (6): 797-805.

Reisinger, Y., and F. Mavondo. 2006. "Cultural Differences in Travel Risk Perception." Journal of Travel \& Tourism Marketing 20 (1): 13-31.

Rittichainuwat, B. N., and G. Chakraborty. 2009. "Perceived Travel Risks Regarding Terrorism and Disease: The Case of Thailand." Tourism Management 30 (3): 410-18.

Roehl, W. S., and D. R. Fesenmaier. 1992. "Risk Perceptions and Pleasure Travel: An Exploratory Analysis." Journal of Travel Research 30 (4): 17-26.

Rohrmann, B. 2008. "Risk Perception, Risk Attitude, Risk Communication, Risk Management: A Conceptual Appraisal." In Global Cooperation in Emergency and Disaster Management, edited by International Emergency Management Society.

Ryan, C. 1993. "Crime, Violence, Terrorism and Tourism: An Accidental or Intrinsic Relationship?" Tourism Management 14 (3): 173-83.

Sarman, I., S. Scagnolari, and R. Maggi. 2016. “Acceptance of LifeThreatening Hazards among Young Tourists: A Stated Choice Experiment." Journal of Travel Research 55 (8): 979-92.

Seabra, C., S. Dolnicar, J. L. Abrantes, and E. Kastenholz. 2013. "Heterogeneity in Risk and Safety Perceptions of International Tourists." Tourism Management 36: 502-10.

Sharifpour, M., G. Walters, and B. W. Ritchie. 2014. "Risk Perception, Prior Knowledge, and Willingness to Travel: Investigating the Australian Tourist Market's Risk Perceptions towards the Middle East." Journal of Vacation Marketing 20 (2): 111-23.
Sharifpour, M., G. Walters, B. W. Ritchie, and C. Winter. 2014. "Investigating the Role of Prior Knowledge in Tourist Decisionmaking: A Structural Equation Model of Risk Perceptions and Information Search." Journal of Travel Research 53 (3): 307-22.

Sönmez, S. F., and A. R. Graefe. 1998a. "Influence of Terrorism Risk on Foreign Tourism Decisions." Annals of Tourism Research 25 (1): 112-44.

Sönmez, S. F., and A. R. Graefe. 1998b. "Determining Future Travel Behavior from Past Travel Experience and Perceptions of Risk and Safety." Journal of Travel Research 37 (2): 171-77.

Um, S., and J. L. Crompton. 1992. "The Roles of Perceived Inhibitors and Facilitators in Pleasure Travel Destination Decisions." Journal of Travel Research 30 (3): 18-25.

UNDP (United Nations Development Programme). 2013. Human Development Report 2013. The Rise of the South: Human Progress in a Diverse World.

UNWTO (World Tourism Organization). 2013a. Tourism Highlights. 2013 edition. Madrid: UNWTO.

UNWTO (World Tourism Organization). 2013b. Yearbook of tourism statistics. Data 2007-2011. Madrid: UNWTO.

Weber, E. U., and W. P. Bottom. 1989. "Axiomatic Measures of Perceived Risk: Some Tests and Extensions." Journal of Behavioral Decision-making 2: 113-31.

Williams, A. M., and V. Baláž. 2013. "Tourism, Risk Tolerance and Competences: Travel Organization and Tourism Hazards." Tourism Management 35:209-21.

Yang, E. C. L., and V. Nair. 2014. "Tourism at Risk: A Review of Risk and Perceived Risk in Tourism." Asia-Pacific Journal of Innovation in Hospitality and Tourism 3 (2): 239-59.

Zuckerman, M. 1971. "Dimensions of Sensation Seeking." Journal of Consulting and Clinical Psychology 36 (1): 45-52.

Zuckerman, M. 2010. "Sensation Seeking." In The Corsini Encyclopedia of Psychology, edited by I. B. Weiner and W. E. Craighead, 1545-47. Hoboken, NJ: Wiley.

\section{Author Biography}

Marion Karl is a research associate at the Department of Geography, University of Munich, Germany. Her research focuses on the destination choice process and relevant influencing factors, among them perceptions of risk. 